\title{
Morphological correlates of community structure in North American waterfowl
}

\author{
P. J. DuBowy
}

\author{
School of Biological and Chemical Sciences, The University of Newcastle, Callaghan, NSW 2308, Australia. \\ Fax: +61 (02) 4921 6923, E-mail: bipjd@cc.newcastle.edu.au.
}

\begin{abstract}
Keywords: Anas, Community structure, Dabbling ducks, Ecomorphology, Foraging ecology, Interspecific competition, Intrapopulation variation, Seasonal effects, Waterfowl.

Abstract: I consider relationships between functional feeding morphology and feeding ecology within a guild of dabbling ducks (Anas spp.) which co-occur year round. This waterfowl guild contains three 'core' species with typical bill morphologies and four 'peripheral' species which vary from the typical morphology in bill length and width or interlamellar spacing. Nearest neighbors in morphological space tend to have high ecological (dietary) overlap; i.e., similarity in morphology corresponds to similarity in ecology. Moreover, by employing Monte Carlo techniques, correlations between morphology and ecology are shown to be weaker during winter than summer, implying that species 'overcompensate' during winter and reduce dietary overlap even more than would be expected by similarities in bill morphology alone. Additionally, I examine morphological variation among populations of North American mallards $(A$. platyrhynchos) to test Roughgarden's (1974) predictions regarding relationships between intraspecific morphological variation and interspecific competition. Specifically, morphological variation should decrease with either an increase in number of competing species or a decrease in available resources. Although populations show expected trends in bill morphology with sex (males have larger bills than females) and latitude (Bergmann's rule), I am able to demonstrate only a weak trend in females in relationship between morphological variation and intensity of interspecific competition. Examinations of relationships between morphology and ecology should be considered during that time of year when ecological 'crunches' occur, as this should be when selection for different morphologies and feeding strategies occurs, although species may utilize other mechanisms (e.g., foraging behavior, habitat selection) which could mediate resource partitioning to a greater degree than would be expected solely by morphological differences.
\end{abstract}

\section{Introduction}

Avian community structure often is characterized by examining a set of resource dimensions (e.g., diet, foraging behavior, or microhabitat selection) and calculating the degree of overlap between species pairs. However, an analysis of functional feeding morphology may present an alternate approach to community structure (Keast 1972, Hespenheide 1973, Karr and James 1975, Abbott et al. 1977, Ricklefs and Cox 1977, Feinsinger et al. 1979, Gatz 1979, Grant and Grant 1980, Ricklefs and Travis 1980, Ricklefs et al. 1981, Simberloff and Boecklen 1981, Wiens and Rotenberry 1981, James 1982, Leisler and Thaler, 1982, Rosenberg et al. 1982, Pöysä 1983, Grant and Schluter 1984, Miles and Ricklefs 1984, Schluter and Grant 1984, Schoener 1986a). In particular, morphological traits may serve as 'indicators' of resource utilization (Roughgarden 1974, Schoener 1974, 1986b, Benkman 1993, Moreno and Carrascal 1993, Koehl 1996). Hence, an overall morphological index may reflect overall re- source utilization of individual species (Rothstein 1973, Grant et al. 1976, Grant and Price 1981, Feinsinger and Swarm 1982). Owing to apparent seasonal variability in competition and community structure (Fretwell 1972, Pöysä 1986ab, DuBowy 1987, 1988, 1991, Green 1998, but see Nudds 1983, Nudds and Bowlby 1984, Bethke 1991, Nudds et al. 1994), I would expect that overlap in morphological space should be more closely related with overlap in ecological space during 'lean' seasons, as this would be the time of year when morphology should be more selected to reduce interspecific competition.

Intrapopulation variation in feeding ecology or morphology may be due to the intensity of interspecific competition that each population experiences. Roughgarden (1974) generated three predictions regarding how competition might affect niche width (equal to the sum of 'between-phenotype' and 'within-phenotype' components where 'between-phenotype' component (BPC) is defined as the variance of the frequency distribution for the differ- 
ent individual averages in the population, and the "withinphenotype' component (WPC) is the average variance of each individual's utilization function). First, with constant species diversity but decreasing environmental productivity, total niche width and BPC should decrease. That is, as the range of resources available to all species decreases, the range of resources utilized by each species also decreases. Second, with fixed environmental productivity but decreasing number of competing species, total niche width and BPC should increase. As the number of competing species decreases, the range of resources utilized by each species should increase. Finally, with decreases in both environmental productivity and species diversity, total niche width should remain constant, while BPC should decrease. This prediction, mathematically formulated in Roughgarden (1974), implies that productivity is more important than the number of competing species in determining BPC; specifically, morphological variation should correlate more strongly with environmental productivity than species diversity. Niche width and morphological variation should decrease with decreasing environmental productivity or increasing numbers of competing species.

To test the first set of predictions, this research examines the morphological correlates of community structure in a guild of shallow-water foraging waterfowl (Anas spp.). Seven congeneric species, Mallard (A. platyrhynchos), Northern Pintail (A. acuta), American Wigeon ( $A$. americana), Gadwall (A. strepera), Northern Shoveler ( $A$. clypeata), Cinnamon Teal (A. cyanoptera), and Greenwinged Teal (A. crecca) co-occur during the winter in the Central Valley of California, USA. These seven species also co-occur during the breeding season in North America, except that Cinnamon Teal is replaced east of the Rocky Mountains by Blue-winged Teal (A. discors), a closely-related ecological equivalent. This guild was used to examine relationships between morphology and community structure and between morphological variability and ecological variability. Pöysä (1983) examined six congeneric European species (including four species also found in North America) and found that whereas neck length may influence water depth favored by each species, bill morphology may influence differences in diet among species foraging at the same depth. Nudds and Bowlby (1984) and Nudds et al. (1994) attempted to correlate bill morphology with foraging ecology, while Nudds and Kaminski (1984) attempted to correlate sexual size dimorphism with resource partitioning in this same guild. All of these studies found few significant correlations, perhaps because they examined community structure during summer when resources are abundant and there is little evidence of interspecific competition
(Nudds 1983; DuBowy 1987, 1988; but see Bethke 1991 for alternative viewpoint). I would expect that feeding morphology should be more closely correlated with foodresource overlap during winter, because species should partition food resources during ecological 'crunches.'

Additionally, North American mallards (here I use a lower case " $\mathrm{m}$ " to designate an ecological type rather than a particular species) exhibit geographical and ecological replacement and provide a useful group with which to test Roughgarden's (1974) predictions of the role that interspecific competition plays in determining intraspecific variation. Currently, the taxonomic status of this group is in question (American Ornithologists' Union 1983, Ankney et al. 1986), and I use trinomials where necessary to differentiate among populations (Bellrose 1976, Palmer 1976). The common Mallard (A. platyrhynchos platyrhynchos) is found throughout most of North America, especially west of the Appalachian Mountains. However, on the East and Gulf Coasts of North America the Mallard is replaced by other populations. In Greenland the Mallard is replaced by Greenland Mallard (A. platyrhynchos conboschas) which looks similar to the nominative Mallard. Other geographical and ecological replacements are dusky, monochromatic forms. Along the Atlantic Coast from the Maritime provinces to Georgia, Mallard is replaced by Black Duck (A. rubripes). In southern Florida and along the Gulf Coast Mallard is replaced by Florida Duck (A. fulvigula fulvigula) (Florida) and Mottled Duck (A. fulvigula maculosa) (Louisiana and Texas), respectively. In the highlands of central Mexico (and formerly north to New Mexico and Arizona) Mallard is replaced by Mexican Duck (A. platyrhynchos diazi). The number of potentially competing congeneric species which co-occur during winter with these forms varies roughly in a northsouth direction (Table 1). Moreover, environmental productivity of these winter areas varies on a north-south gradient as well. Consequently, some mallards winter in very productive areas with few competing species, other mallards winter in productive areas with many competing species, and still other mallards winter in less productive areas with few competing species. These gradients in environmental productivity and numbers of syntopic species permit testing of Roughgarden's (1974) predictions. These predictions for North American mallards are summarized in Table 1 and are as follows: Florida (fulvigula) Ducks should show the greatest degree of morphological variation and largest niche width as they winter in highly productive areas with few potentially competing species. Mottled Ducks (maculosa) also winter in very productive areas, but six congeneric species co-occur during winter. Consequently, morphological variation and niche width are predicted to decrease (prediction 2, above). Con- 
Table 1. Predictions of morphological variation in North American mallards (based on Roughgarden 1974).

\begin{tabular}{|c|c|c|}
\hline \multirow{2}{*}{$\begin{array}{l}\text { Geographic Area } \\
\text { Species } \\
\text { (Species Diversitya ; Productivity) }\end{array}$} & \multicolumn{2}{|c|}{ Predictions: } \\
\hline & $\begin{array}{c}\text { Morphological } \\
\text { Variation b }\end{array}$ & $\begin{array}{l}\text { Niche } \\
\text { Widthb }\end{array}$ \\
\hline \multicolumn{3}{|l|}{ Greenland } \\
\hline Greenland Mallard & LOW & STAY THE SAME \\
\hline (Very low 0,$1 ;$ Very low) & $\Uparrow$ & $\uparrow$ \\
\hline New England and Middle Atlantic region & & $\uparrow$ \\
\hline Black Duck ${ }^{\mathrm{c}}$ & & LOW \\
\hline (Low 1,2; Low) & $\Uparrow$ & $\Uparrow$ \\
\hline Mexico and SW U.S. & & \\
\hline $\begin{array}{l}\text { Mexican Duck } \\
\text { (Low 2,2; High?) }\end{array}$ & $\Uparrow$ & $\Uparrow$ \\
\hline Florida & $\Uparrow$ & $\Uparrow$ \\
\hline Florida Duck & HIGH & HIGH \\
\hline (Low 1,3; Very high) & $\Downarrow$ & $\Downarrow$ \\
\hline Gulf Coast & $\Downarrow$ & $\Downarrow$ \\
\hline $\begin{array}{l}\text { Mottled Duck } \\
\text { (High 6,1; Very high) }\end{array}$ & LOW & LOW \\
\hline
\end{tabular}

${ }^{a}$ Numbers for species diversity refer to the number of congeneric species which commonly and occasionally winter with these species, respectively. ${ }^{\mathrm{b}}$ Arrows indicate direction of decreasing morphological variation or niche width. ${ }^{\mathrm{c}}$ Black Ducks winter along the east coast of the United States where winter conditions and productivity vary, with typically harsh winters in the northern part of the range (Canada and New England), and milder conditions along the southern portion of the range (Chesapeake Bay and Carolinas).

versely, Black (rubripes) and Mexican (diazi) Ducks both also winter in areas with few competing species, but environmental productivity in these areas during winter also is reduced. Consequently, morphological variation and niche width again are predicted to decrease (prediction 1, above). Further north, Greenland Mallards (conboschas) winter in environmentally poor areas with virtually no other congeneric species. Polymorphism should further decrease, while niche width should not decrease further (prediction 3, above).

\section{Methods}

Specimens were measured at the Museum of Vertebrate Zoology, University of California, Berkeley, the Academy of Natural Sciences of Philadelphia, the American Museum of Natural History (New York), the National Museum of Natural History (Washington, D.C.), and the
Reading Public Museum (Reading, Pennsylvania). I tested relationships between morphological variation and resource utilization or community structure by examining museum specimens of the representative species and generating an index of morphological space by collecting data on a series of morphological parameters concerned with foraging - bill length, culmen length, bill width, bill perimeter, number of lamellae, nail width, hind toe length, and tarsal length (index of body size). I also derived an index of interlamellar spacing by dividing perimeter by number of lamellae. For the waterfowl community structure study I used only birds collected during winter in the Central Valley of California. For the mallard study, I divided Black Ducks into two populations, a northern population, individuals of which were collected in New England or the maritime provinces of Canada, and a southern population, individuals of which were col- 
lected in the Carolinas, because environmental conditions are not uniform throughout the winter range of Black Ducks; northern populations usually experience much harsher conditions (D. Jorde, pers. comm.). Most museum specimens were collected during the early part of the $20^{\text {th }}$ century before extensive hybridization between forms occurred (Palmer 1976). Consequently, introgression is not a cause of morphological variation either within or among populations (museum specimens) and can be ignored in this study.

Variation within species was measured by calculating the morphological variance of all normalized (log-transformed) morphological variables. Before calculating variances, each log-transformed variable was transformed further by subtracting the mean value for that variable from each value of that variable. This caused the mean values of each transformed parameter to equal zero, and any differences in total variance among species would be due to real variation and not due to different scalings of each population. The variances of each parameter were summed to give a total morphological variance for the population, and this total variance is equal to the sum of the eigenvalues of the principal components matrix (Pimentel 1979).

For the waterfowl community study, overlap or similarity between species pairs was measured by means of Principal Component Analysis (PCA) and by calculating mean nearest neighbor distances (Ricklefs and Travis 1980). PCA of the above-measured morphological parameters yielded an index of the size of the morphological space occupied by the entire set of species, while mean nearest neighbor distances gave a measure of density of species packing. The latter measurements then were compared to seasonal resource utilization indices to test if species packing in morphological space is correlated with species packing in ecological space. Specifically, speciespair overlaps in ecological space were plotted against overlap in morphological space. Ecological overlap values $(D i j)$ for species pairs were taken from DuBowy (1987, 1988), whereas morphological similarity values were calculated by using the formula from Ricklefs and Travis (1980):

$d_{i j}=\left[\sum\left(X_{i k}-X_{j k}\right)^{2}\right]^{1 / 2}$

where $d_{i j}$ is the Euclidean morphological distance between species pairs, and $X_{i k}$ and $X_{j k}$ are the mean values of the logarithms of morphological parameter $k$ for species $i$ and $j$, respectively. For the mallard study, stepwise discriminant analyses were performed to differentiate among populations. Additionally, total morphological variance for each population was calculated as described above.

\section{Results}

\section{Waterfowl community structure}

Based on morphological parameters, the seven Anas species which occur syntopically during winter exhibit striking differences from one another (Table 2, Fig. 1). PCA reveals a central cluster of three species (Cinnamon Teal, Northern Pintail, and Gadwall) with more 'typical' bill morphologies surrounded by four 'peripheral' species (Green-winged Teal, Northern Shoveler, Mallard, and American Wigeon). The component loadings (both unrotated and rotated) indicate that component 1 comprises mainly culmen length, bill width, perimeter length, and number of lamellae, while component 2 comprises mainly nail width and interlamellar spacing (Table 3). These two components account for $94.8 \%$ of the variance among species. Northern Shovelers have widened, elongated bills with small interlammelar spacings. Conversely, American Wigeon have short, stubby bills with moderate interlamellar spacings, and Mallards have moderatelysized bills with wide interlamellar spacings. Total variance within species also shows an interesting trend. Northern Shoveler, the most specialized forager, has the lowest total variance for males and a close second for females (Table 2). Conversely, Green-winged Teal, one of the more generalized species, has the highest total variance for males and females.

Examination of the ecological overlap values (DuBowy 1987, 1988) of nearest neighbors in morphological space yields surprising results. Six of the seven overlap values for nearest morphological neighbors have six of the eight highest values for food overlap during winter (Fig. 1, see also DuBowy 1988). The lone exception is Northern Shoveler which has the greatest nearest neighbor distance and which during winter does not show a high overlap value with any other species (DuBowy 1988, 1996). The three core species also show high ecological overlap values among each other.

When ecological overlap (determined by overlap in food items) is plotted against morphological distance by season, several seasonal differences are apparent (Fig. 2a,b). During summer some species pairs exhibit high overlaps for food items $\left(D_{i j}=0.3-0.5\right)$, even though they are morphologically dissimilar $\left(d_{i j}=1.6-2.0\right)$. However, this pattern is not found in winter. During winter, species pairs which are morphologically dissimilar show low overlap values for food items $\left(D_{i j}=0.02-0.2\right)$. Additionally, the entire winter plot lies closer to the abscissa (i.e., 
Table 2. Means of variables and total variance for wintering ducks.

\begin{tabular}{|c|c|c|c|c|c|c|c|}
\hline Species ${ }^{a}$ : & MALL & PINT & GADW & WIGN & SHOV & CNTL & GWTL \\
\hline \multicolumn{8}{|l|}{ Males: } \\
\hline $\mathrm{N}$ & 13 & 21 & 10 & 32 & 40 & 18 & 15 \\
\hline Culmen & 55.254 & 51.814 & 42.935 & 35.892 & 65.204 & 45.478 & 37.077 \\
\hline Width & 22.323 & 18.883 & 17.100 & 16.463 & 29.796 & 17.125 & 13.317 \\
\hline Nail & 7.623 & 5.933 & 5.683 & 6.345 & 5.681 & 5.733 & 3.357 \\
\hline Perimeter & 64.154 & 61.619 & 51.100 & 40.594 & 78.625 & 51.278 & 44.867 \\
\hline Lamellae & 42.077 & 48.667 & 44.600 & 32.469 & 111.775 & 51.833 & 48.000 \\
\hline Space & 1.526 & 1.267 & 1.148 & 1.251 & 0.657 & 0.990 & 0.936 \\
\hline $\begin{array}{l}\text { Total } \\
\text { Varianceb }\end{array}$ & 1.279 & 1.194 & 1.209 & 1.275 & 1.082 & 1.186 & 1.400 \\
\hline \multicolumn{8}{|l|}{ Females: } \\
\hline $\mathrm{N}$ & 15 & 15 & 11 & 6 & 12 & 12 & 13 \\
\hline Culmen & 52.270 & 47.183 & 40.673 & 34.900 & 60.533 & 43.767 & 35.381 \\
\hline Width & 21.810 & 18.143 & 16.709 & 15.092 & 28.425 & 16.479 & 12.792 \\
\hline Nail & 7.443 & 5.683 & 5.909 & 5.892 & 5.704 & 5.775 & 3.354 \\
\hline Perimeter & 61.933 & 56.400 & 47.727 & 39.167 & 72.500 & 47.750 & 42.308 \\
\hline Lamellae & 40.933 & 47.133 & 43.091 & 30.333 & 113.667 & 46.750 & 42.306 \\
\hline Space & 1.518 & 1.200 & 1.108 & 1.292 & 0.638 & 1.022 & 0.914 \\
\hline $\begin{array}{l}\text { Total } \\
\text { Varianceb }\end{array}$ & 1.335 & 1.255 & 1.166 & 1.327 & 1.168 & 1.275 & 1.387 \\
\hline
\end{tabular}

${ }^{\mathrm{a}}$ Species: MALL $=$ Mallard, PINT $=$ Northern Pintail, GADW $=$ Gadwall, WIGN $=$ American Wigeon, SHOV $=$ Northern Shoveler, $\mathrm{CNTL}=$ Cinnamon Teal, GWTL $=$ Green-winged Teal. ${ }^{\mathrm{b}}$ Total variance is the sum of the variances for each character.

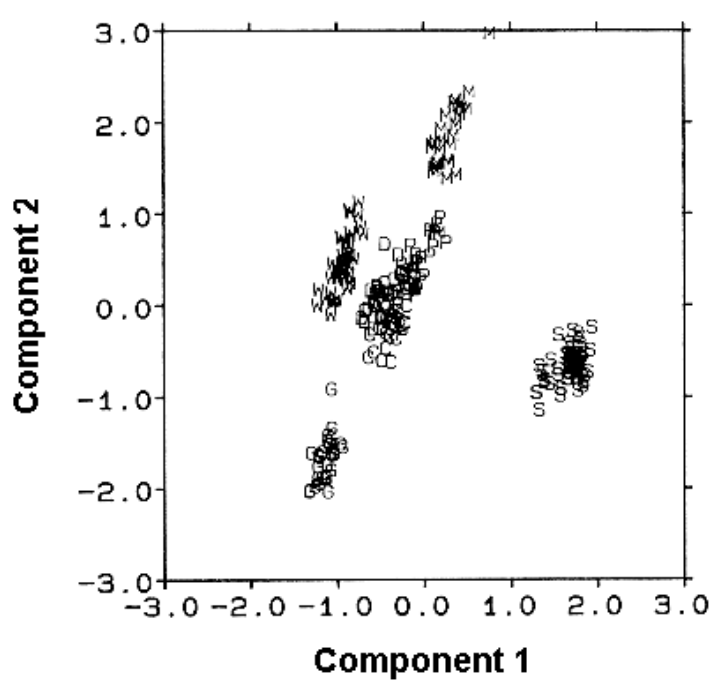

Figure 1. Principal components analysis of bill morphologies of co-occurring dabbling ducks. $\mathrm{C}=$ Cinnamon Teal; $\mathrm{D}=$ Gadwall; $\mathrm{G}=$ Green-winged Teal; $\mathrm{M}=$ Mallard; $\mathrm{P}=$ Northern Pintail; $\mathrm{S}=$ Northern Shoveler; $\mathrm{W}=$ American Wigeon. the plot appears 'compressed'), due to the fact that virtually all food overlap values between species pairs decrease in winter. The slopes of the linear regressions through the summer and winter points are almost equal, with a lower y-intercept in winter, implying a similar morphology/ecology relationship during both seasons. However, the product-moment correlation coefficient for summer is better $\left(r_{s}=-0.887\right)$ than the corresponding correlation coefficient for winter $\left(r_{w}=-0.301\right)$, implying a closer fit between morphology and ecology during summer.

Statistical tests on the correlation between overlap in feeding morphology and food types were conducted using Monte Carlo techniques. Simple linear regression statistics were not appropriate due to the nonindependence of pairwise points. Instead, the summer and winter values for food overlap (Fig. 2) were randomly interchanged. Because morphology did not change between seasons, the only variant between seasons was overlap in food types. Product-moment correlation coefficients were calculated on the hypothetical (randomized) summer and winter 
Table 3. Component loadings for bill morphology of wintering waterfowl.

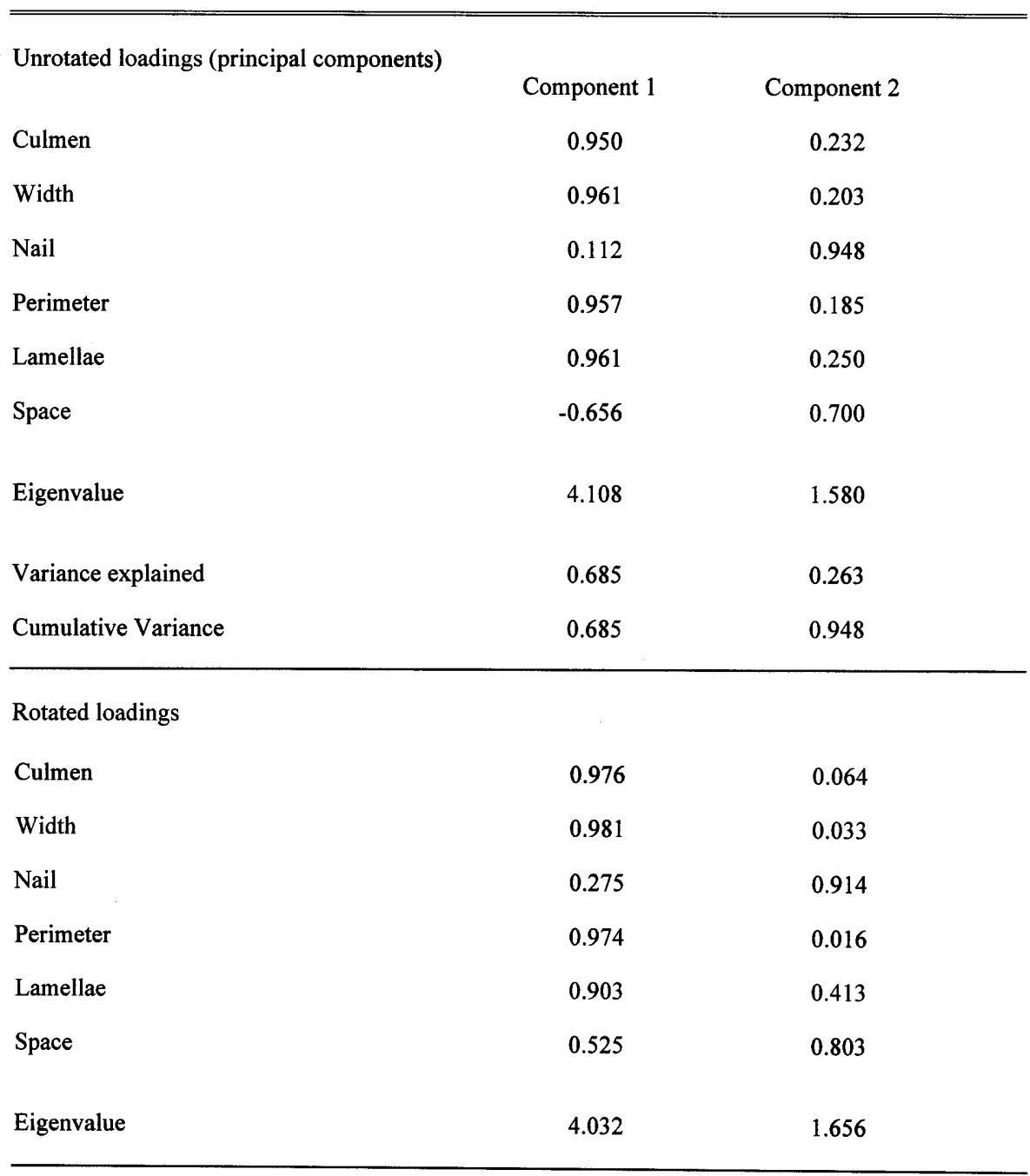

$\mathbf{a}$

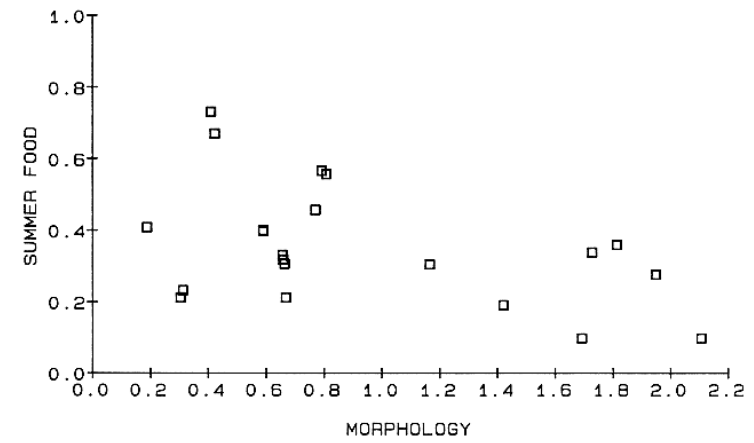

b

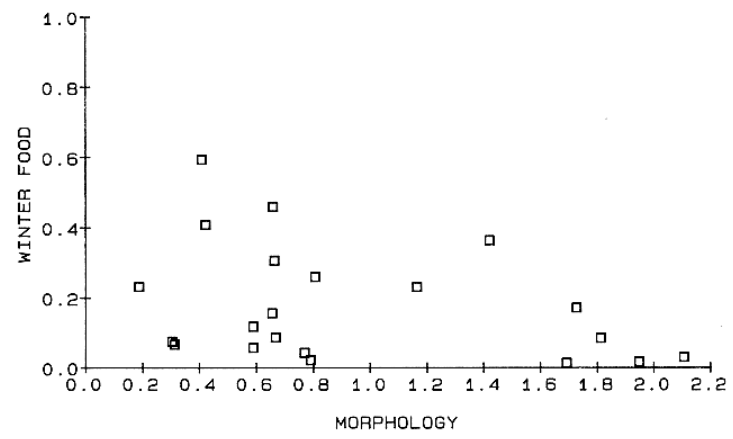

Figure 2. Ecological (food) overlap plotted against morphological distance for all species pairs during summer (a) and winter (b). 
communities. The exact probability of the statistical significance of the winter versus summer relationship was calculated as the number of iterations in which the difference between the product-moment correlation coefficient for the hypothetical winter community and the corresponding summer correlation coefficient was less than or equal to $0.586\left(r_{w}-r_{s}\right)$, divided by the number of total hypothetical relationships constructed (number of iterations of the model $=100,000)$. Concurrently, the actual summer and winter points (Fig. 2) were tested to see if the product-moment correlation coefficients differed significantly from random. The product-moment correlation coefficient of each hypothetical summer or winter community was compared to the correlation coefficients of the actual summer $\left(r_{s}=-0.887\right)$ and winter $\left(r_{w}=-0.301\right)$ relationships. The exact probabilities of the significance of the correlation coefficients for winter and summer were calculated as the number of random relationships with product-moment correlation coefficients more negative (i.e., smaller) than the corresponding actual correlation coefficients divided by the total number of correlation coefficients generated (total iterations $=100,000$ ). Of the three correlation-coefficient statistics generated, the only one which was statistically significant was whether the summer morphology/food plot was statistically different than random $(p=0.0015)$. The difference between winter and summer correlation coefficients was non-significant $(p=0.3555)$, while in the case of the winter plot, the probability was also non-significant ( $p=0.9517$ ), owing primarily to the scatter of points at the low end of the graph (i.e., near the origin). The product-moment correlation coefficient for the winter relationship being less significant than that for summer implies that species with similar bill morphologies 'overcompensate' and reduce their food overlap more than would be expected based solely on differences in bill morphology, perhaps by employing other mechanisms (e.g., foraging behavior, habitat segregation) to reduce overlap in food items taken by each species.

\section{Intraspecific variation in North American mallards}

Based on stepwise discriminant analysis, North American mallards exhibit typical trends in bill morphology (Fig. 3). Based on the mean values for the group centroids, bills of males are larger than females (canonical variable 1) and both sexes (especially females) exhibit Bergmann's rule, i.e., increasing bill size with increasing latitude (from Mexican and Mottled Duck to Greenland Mallards) (canonical variable 2). Bill size is roughly correlated with body size in Anas (in fact, bill size is occasionally used as a measure of body size), so the bills of these birds agree with Bergmann's rule, rather than contradict Allen's rule of decreasing appendage size with in-

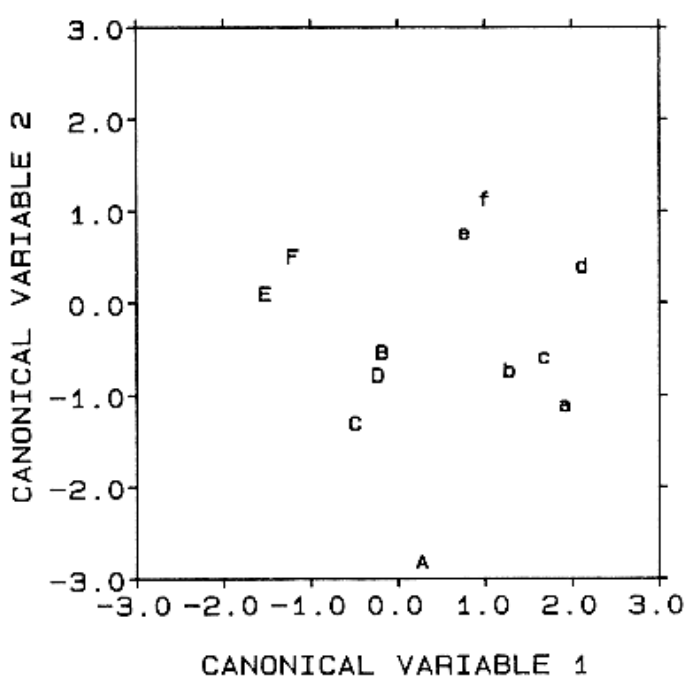

Figure 3. Means of centroids from discriminant function analysis of morphologies of North American mallards. Males are designated by capital letters, females by lowercase letters. Symbols: A, a = Greenland Mallard; B, b = northern Black Duck; C, c = southern Black Duck; D, $d=$ Mexican Duck; E, e = Mottled Duck; F, f = Florida Duck.

creasing latitude. However, an examination of means and variances for various morphological characteristics (Table 4) does not show much agreement with Roughgarden's (1974) predictions (Table 1). In females, the highest population variance is found in Florida Ducks, as predicted, and variance decreases both towards Mottled Ducks and towards Greenland Mallards, although not in a uniform progression. In males, the predicted trend is not discernible; if anything the trend is reversed, with variance increasing going both towards Mottled Ducks and Greenland Mallards.

\section{Discussion}

Differences in bill morphology among closely related waterfowl species and concomitant differences in foraging and food items have been known for years (Lack 1974, Pöysä 1983). However, these differences have never before been examined with regard to seasonal variation in waterfowl community structure. Because bill morphology is an immutable characteristic once adult size is attained (unlike seasonally variable internal organs), an obvious question is what is the cost of a bill morphology which might hinder foraging optimization during 'fat' seasons, i.e., times when foraging specialization is not necessary and, indeed, may be counter productive. The cost associated with the 'wrong' bill morphology (perhaps expressed as an increase in capture or handling 
Table 4. Means of variables and total variance for North American mallards.

\begin{tabular}{|c|c|c|c|c|c|c|}
\hline \multicolumn{2}{|c|}{ Greenland } & \multirow{2}{*}{$\begin{array}{c}\text { N.Black } \\
\leftarrow \\
\leftarrow\end{array}$} & \multirow{2}{*}{$\begin{array}{c}\text { S.Black }{ }^{\mathrm{a}} \\
\leftarrow\end{array}$} & \multirow{2}{*}{$\begin{array}{c}\text { Mexican } \\
\leftarrow\end{array}$} & \multirow{2}{*}{$\begin{array}{c}\text { Florida } \\
\leftarrow \text { High } \rightarrow\end{array}$} & \multirow{2}{*}{$\begin{array}{c}\text { Mottled } \\
\text { Low }\end{array}$} \\
\hline Variation b: & Low & & & & & \\
\hline \multicolumn{7}{|l|}{ Males: } \\
\hline $\mathrm{N}$ & 17 & 8 & 13 & 20 & 56 & 41 \\
\hline Clumen & 51.723 & 52.164 & 53.919 & 53.860 & 54.870 & 56.157 \\
\hline Width & 21.224 & 20.600 & 22.123 & 21.733 & 23.117 & 23.122 \\
\hline Length & 60.879 & 61.025 & 60.938 & 61.442 & $61: 021$ & 62.824 \\
\hline Nail & 7.494 & 7.963 & 7.450 & 8.053 & 8.001 & 7.943 \\
\hline Perimeter & 64.000 & 61.875 & 64.462 & 61.700 & 61.964 & 63.854 \\
\hline Lamellae & 46.118 & 44.750 & 43.385 & 44.850 & 45.321 & 45.390 \\
\hline Tarsus & 45.085 & 44.706 & 43.431 & 45.930 & 44.857 & 44.689 \\
\hline Hind Toe & 11.518 & 10.731 & 11.000 & 10.953 & 10.959 & 10.818 \\
\hline Space & 1.391 & 1.384 & 1.489 & 1.380 & 1.370 & 1.410 \\
\hline Total Varc & 2.040 & 2.078 & 1.927 & 1.973 & 2.007 & 2.175 \\
\hline \multicolumn{7}{|l|}{ Females: } \\
\hline $\mathrm{N}$ & 7 & 7 & 12 & 18 & 36 & 30 \\
\hline Culmen & 49.586 & 52.164 & 50.946 & 50.552 & 51.344 & 52.085 \\
\hline Width & 20.393 & 20.600 & 20.583 & 20.403 & 21.654 & 21.697 \\
\hline Length & 56.914 & 59.286 & 56.554 & 56.219 & 55.517 & 57.742 \\
\hline Nail & 7.657 & 7.321 & 7.517 & 7.814 & 7.853 & 7.753 \\
\hline Perimeter & 58.429 & 60.000 & 59.333 & 56.722 & 57.333 & 58.900 \\
\hline Lamellae & 44.286 & 44.143 & 42.333 & 44.278 & 43.639 & 44.900 \\
\hline Tarsus & 43.371 & 43.179 & 41.863 & 42.131 & 42.424 & 41.965 \\
\hline Hind Toe & 10.871 & 10.914 & 10.800 & 10.853 & 10.926 & 10.315 \\
\hline Space & 1.321 & 1.363 & 1.404 & 1.283 & 1.315 & 1.314 \\
\hline Total Varc & 2.077 & 2.135 & 2.071 & 1.915 & 2.189 & 2.105 \\
\hline
\end{tabular}

${ }^{a}$ Black Ducks were divided into northern and southern populations (see Methods). ${ }^{b}$ Morphological variation predictions based on Table $1 .{ }^{\mathrm{c}}$ Total Variance is the sum of the variances for the listed characters.

time/energy) is probably offset by a reduction in search time by foraging on an abundant food type (DuBowy 1997). Conversely, foraging shifts by Anas species in the presence or absence of potentially competing congeneric species have been observed in Europe (Pöysä 1986ab, Green 1998). The effects of a static bill morphology on foraging shifts are not known.

Ricklefs and Travis (1980) attempted to correlate morphological similarity and ecological overlap for 11 temperate-zone scrub communities described by Cody (1974). Unfortunately, Cody (1974) did not tabulate or categorize the feeding behaviors of these scrubland birds. Consequently, Ricklefs and Travis (1980) were unable to correlate morphology and feeding, but rather, were forced to attempt to correlate morphology with overlap in habitat distribution and vertical foraging height. Species pairs widely dissimilar in morphology often had high ecological overlap values. Miles and Ricklefs (1984) were able to show a correlation between morphology and foraging, but the relationships were between morphology and foraging behavior (attack mode, perch height, etc.) rather than food type. 
The mallard data, however, do not support Roughgarden's (1974) predictions on population variation in response to interspecific competition. Although the trend roughly holds for females (Florida Ducks have the most variability and variance decreases towards both Mottled Ducks and Greenland Mallards), the trend does not hold for males. In fact, for males the trend is nearly reversed. This may be due to at least three factors. First, with decreasing available resources species ideally should contract their resource utilization around some core of optimally exploited resources. Roughgarden (1974) predicted that productivity is more important than the number of competing species in determining the BPC; specifically, morphological variation should correlate more strongly with environmental productivity than species diversity. Such a contraction does not occur in North American mallards during winter from south to north. Rather, northern populations (Black Ducks and Greenland Mallards) are utilizing resources not present (or available) in the diets of southern forms (e.g., mollusks) (Palmer 1976). Second, the catholic diet of mallards may preclude any attempt to measure niche breadth as a function of resource productivity and interspecific competition. While environmental productivity decreases during winter from south to north, mallards shift their foraging to other more abundant resources. This major shift in resource utilization and the wide range of prey items taken might make mallards inappropriate for testing Roughgarden's (1974) hypotheses. Perhaps only species which have fairly narrow diets (e.g., insectivorous lizards) may be appropriate for testing. Third, as with the community structure data, there may be little correlation between morphology and winter ecology. Species pairs (including a mallard form at each location) may reduce overlap more than would be expected based solely on bill morphology. If this were true, feeding morphology within a population might vary independently of interspecific competition or resource abundance.

Typically, studies relate morphology to niches during the breeding season (Ricklefs and Travis 1980, Miles and Ricklefs 1984, Nudds and Bowlby 1984, Nudds and Kaminski 1984, Nudds et al. 1994, but see Grant et al. 1976, Grant and Schluter 1984, Schluter and Grant 1984). Alternatively, I propose that morphological correlations with feeding ecology or community structure should also be examined during the winter season (or other time of year when resources are in short supply). During these periods interspecific competition may be intense, and reliance on morphologically-mediated feeding strategies which reduce this competition may be high. However, it should also be noted that organisms have additional mechanisms (such as foraging behavior or habitat selec- tion) which further may reduce interspecific competition for food resources. Consequently, species-pairs may have lower food overlap than predicted by morphology alone, as demonstrated in Figure 2. Although differences in bill morphology may enhance resource partitioning during 'fat' times (Nudds and Bowlby 1984, Nudds et al. 1994), I propose that interspecific differences in morphology should be considered, in part, to also explain resource partitioning during 'lean' seasons. An integrated morphological/behavioral/ecological approach should be adopted when attempting to discerne differences in community organization.

Acknowledgements: Research funding for this project was provided by a Jessup Research Fellowship from the Academy of Natural Sciences of Philadelphia. Additional funding was provided by a Josselyn Van Tyne Award from the American Ornithologists' Union, a Frank M. Chapman Grant from the American Museum of Natural History, a Grant-in-Aid of Research from the Society of Sigma Xi, and an Earle C. Anthony Graduate Fellowship and Jastro Research Scholarships from the University of California, Davis. I thank C. A. Toft, the late D. G. Raveling, and especially T. W. Schoener, for help and discussions concerning this research. Discussions with D. Miles, H. Pöysä, R. Ricklefs and D. Schluter helped elucidate the role of morphology in community structure. R. Swihart, T. Nudds and $\mathrm{J}$. Rotenberry offered suggestions on previous drafts of this manuscript. I thank N. K. Johnson (Museum of Vertebrate Zoology, University of California, Berkeley), F. B. Gill (Academy of Natural Sciences of Philadelphia), L. L. Short (American Museum of Natural History), R. D. Zusi (National Museum of Natural History), and B. Dietrich (Reading Public Museum) for access to their collections. I also thank the staff of the Academy of Natural Sciences of Philadelphia and the Department of Biology, University of Pennsylvania, for the hospitality shown me during my stay in Philadelphia.

\section{References}

Abbott, I, L.K Abbott, and P.R. Grant. 1977. Comparative ecology of Galapagos ground finches (Geospiza Gould): evaluation of the importance of floristic diversity and interspecific competition. Ecol. Monogr. 47: 151-184.

American Orinthologists' Union. 1983. Check-list of North American Birds, 6th edition, Washington, D.C., American Orinthologists' Union.

Ankney, C.D., D.G. Dennis, L.N. Wishard, and J.E. Seeb. 1986. Low genetic variation between black ducks and mallards. Auk 103: 701-709.

Bellrose, F.C. 1976. Ducks, Geese and Swans of North America. Stackpole Books, Harrisburg, Pennsylvania, USA.

Benkman, C. W. 1993. Adaptation to single resources and the evolution of crossbill (Loxia) diversity. Ecol. Monogr. 63: 305-325.

Bethke, R.W. 1991. Seasonality and interspecific competition in waterfowl guilds: a comment. Ecology 72: 1155-1158.

Cody, M.L. 1974. Competition and the Structure of Bird Communities. Princeton University Press, Princeton, New Jersey, USA.

DuBowy, P.J. 1987. Seasonal variation in the structure of North American waterfowl communities. PhD Dissertation, University of California, Davis, California, USA. 
DuBowy, P.J. 1988. Waterfowl communities and seasonal environments: temporal variability in interspecific competition. Ecology 69: 1439-1453.

DuBowy, P.J. 1991. Seasonality and interspecific competition in waterfowl guilds: patterns and processes - a reply to Bethke. Ecology 72: 1159-1161.

DuBowy, P.J. 1996. Northern Shoveler (Anas clypeata). In: A. Poole and F. Gill (eds), The Birds of North America, No. 217. Academy of Natural Sciences of Philadelphia and American Ornithologists Union, Washington, DC.

DuBowy, P.J. 1997. Long-term foraging optimization in northern shovelers. Ecol. Model. 95:119-132.

Feinsinger, P., R.K. Colwell, J. Terborgh, and S.B. Chaplin. 1979. Elevation and the morphology, flight energetics, and foraging ecology of tropical hummingbirds. Amer. Nat. 113: 481-497.

Feinsinger, P. and L.A. Swarm. 1982. "Ecological release," seasonal variation in food supply, and the hummingbird Amazilia tobaci on Trinidad and Tobago. Ecology 63: 1574-1587.

Fretwell, S.D. 1972. Populations in a Seasonal Environment. Princeton University Press, Princeton, New Jersey, USA.

Gatz, A.J. 1979. Community organization in fishes as indicated by morphological features. Ecology 60: 711-718.

Grant, P.R. and B.R. Grant. 1980. The breeding and feeding characteristics of Darwin's finches on Isla Genovesa, Galapagos. Ecol. Monogr. 50: 381-410.

Grant, P.R., B.R. Grant, J.N.M. Smith, I.J. Abbott, and L.K. Abbott 1976. Darwin's finches: population variation and natural selection. Proceedings of the National Academy of Sciences (USA) 73: $257-261$.

Grant, P.R. and T.D. Price. 1981. Population variation in continuously varying traits as an ecological genetics problem. Amer. Zool. 21: 795-811.

Grant, P.R. and D. Schluter. 1984. Interspecific competition inferred from patterns of guild structure. In D.R. Strong, D.S. Simberloff, L.G. Abele, and A.D. Thistle (eds). Ecological Communities: Conceptual Issues and the Evidence. Princeton University Press, Princeton, New Jersey, USA, pp. 201-233.

Green, A.J. 1998. Comparative feeding behaviour and niche organization in a Mediterranean duck community. Can. J. Zool. 76: 500-507.

Hespenheide, H.A. 1973. Ecological inferences from morphological data. Ann. Rev. Ecol. Syst. 4: 213-229.

James, F.C. 1982. The ecological morphology of birds: a review. Annales Zoologici Fennici 19: 265-275.

Karr, J.R. and F.C. James. 1975. Eco-morphological configurations and convergent evolution in species and communities. In: M.L. Cody and J.M. Diamond (eds.). Ecology and Evolution of Communities. Belknap Press, Cambridge, Massachusetts, USA, pp. 258-291.

Keast, A. 1972. Ecological opportunities and dominant families, as illustrated by the neotropical Tyrannidae (Aves). Evolutionary Biology 4: 229-277.

Koehl, M.A.R. 1996. When does morphology matter? Ann. Rev. Ecol. Syst. 27: 501-542.

Lack, D. 1974. Evolution Illustrated by Waterfowl. Harper and Row, New York, New York, USA

Leisler, B. and E. Thaler. 1982. Differences in morphology and foraging behavior in the goldcrest Regulus regulus and firecrest $R$. ignicapillus. Annales Zoologici Fennici 19: 277-284.
Miles, D.B. and R.E. Ricklefs. 1984. The correlation between ecology and morphology in deciduous forest passerine birds. Ecology 54: 1629-1640.

Moreno, E. and L. M. Carrascal. 1993. Leg morphology and feeding postures in four Parus species: an experimental ecomorphological approach. Ecology 74: 2037-2044.

Nudds, T.D. 1983. Niche dynamics and organization of waterfowl guilds in variable environments. Ecology 64: 319-330.

Nudds, T.D. and J.N. Bowlby. 1984. Predator-prey size relationships in North American dabbling ducks. Can. J. Zool. 62: 2002-2008

Nudds, T.D. and R.M. Kaminski. 1984. Sexual size dimorphism in relation to resource partitioning in North American dabbling ducks. Can. J. Zool. 62: 2009-2012.

Nudds, T.D., K. Sjöberg, and P. Lundberg. 1994. Ecomorphological relationships among Palearctic dabbling ducks on Baltic coastal wetlands and a comparison with the Nearctic. Oikos 69: 295 303.

Palmer, R.S. 1976. Handbook of North American Birds, vol. 2. Yale University Press, New Haven, Connecticut, USA.

Pimentel, R.A. 1979. Morphometrics. The Multivariate Analysis of Biological Data. Kendall/Hunt Publishing Company, Dubuque, Iowa, USA.

Pöysä, H. 1983. Morphology-mediated niche organization in a guild of dabbling ducks. Ornis Scandinavica 14: 317-326.

Pöysä, H. 1986a. Foraging niche shifts in multispecies dabbling duck (Anas spp.) feeding groups: harmful and beneficial interactions between species. Ornis Scandinavica 17: 333-346.

Pöysä, H. 1986b. Species composition and size of dabbling ducks (Anas spp.) feeding groups: are foraging interactions important determinants? Ornis Fennica 63: 33-41.

Ricklefs, R.E., D. Cochran, and E.R. Pianka. 1981. A morphological analysis of the structure of communities of lizards in desert habitats. Ecology 62: 1474-1483.

Ricklefs, R.E. and G.W. Cox. 1977. Morphological similarity and ecological overlap among passerine birds on St. Kitts, British West Indies. Oikos 29: 60-66.

Ricklefs, R.E. and J. Travis. 1980. A morphological approach to the study of avian community organization. Auk 97: 321-338.

Rosenberg, K.V., R.D. Ohmart, and B.W. Anderson. 1982. Community organization of riparian breeding birds: response to an annual resource peak. Auk 99: 260-274.

Rothstein, S.I. 1973. The niche-variation model - is it valid? Amer Nat. 107: 598-620.

Roughgarden, J. 1974. Niche width: biogeographic patterns among Anolis lizard populations. Amer. Nat. 108: 429-442.

Schluter, D. and P.R. Grant. 1984. Ecological correlates of morphological evolution in a Darwin's finch, Geospiza difficilis. Evolution 38: 856-869.

Schoener, T.W. 1974. Resource partitioning in ecological communities. Science 185: 27-39

Schoener, T.W. 1986a. Mechanistic approaches to community ecology: a new reductionism. Amer. Zool. 26: 81-106.

Schoener, T.W. 1986b. Resource partitioning. In: J. Kikkawa and D.J. Anderson (eds.). Community Ecology: Pattern and Process. Blackwell, Oxford, England.

Simberloff, D. and W. Boecklen. 1981. Santa Rosalia reconsidered size ratios and competition. Evolution 35: 1206-1228.

Wiens, J.A. and J.T. Rotenberry. 1981. Morphological size ratios and competition in ecological communities. Amer. Nat. 117: 592599. 